\title{
Influence of Transport Phenomena on Pollutants Concentration in Mediterranean Tunisian Regions
}

\author{
${ }^{1,2}$ Karim Bouchlaghem, ${ }^{1}$ Blaise Nsom and ${ }^{3}$ Jean-Francois Dorville \\ ${ }^{1}$ Université de Bretagne Occidentale, LBMS-EA 4325, Université Européenne de Bretagne, \\ BP 93169, Rue de Kergoat, 29231, BREST Cedex 3, France \\ ${ }^{2}$ Unité de Recherche « Energétique et Environnement » (03/ UR 13-06), \\ Université de Kairouan-Av. Med Ibn Sahnoun, 3100 Kairouan, Tunisia and \\ Institut Supérieur des Sciences Appliquées et de Technologie de Sousse, \\ Université de Sousse, Cité Taffala, 4003 Sousse Ibn Khaldoun, Tunisia \\ ${ }^{3}$ Department of Physics, Faculty of Science and Technology, \\ University of West Indies, Mona Campus, Kingston 6, Jamaica
}

Received 2013-08-07; Revised 2014-01-21; Accepted 2014-01-23

\begin{abstract}
The objective of this study is to investigate the origin of the polluted air masses in the Tunisian Mediterranean regions and to characterize the atmospheric conditions and the transport and dispersion mechanisms that give rise to pollution events. For this end, we conducted continuous measurements campaigns of surface ozone concentration and meteorological parameters during summer 2011 using mobile and fixed stations in the Tunisian regions. The results indicated that the seasonal variability of ozone concentrations was related to European and Saharan transport events. Long range transport of pollutants from Europe resulted in $\mathrm{O}_{3}$ loading and frequent surpassing of the European standard limits in the Mediterranean Tunisian sites. During these events, the weather conditions support photochemical phenomena. The Saharan events provided the importance of chemical reactions and radiative impact involving dust particles which may reduce the photochemical production of ozone.
\end{abstract}

Keywords: Mediterranean, Transport, Air Quality, Pollutants Monitoring, Standards Limits

\section{INTRODUCTION}

The Mediterranean basin, characterized by frequent fires, recirculation near the coasts, dust plumes transport from Sahara and intense solar radiation, represents a region particularly affected by air pollution events (Carnevale et al., 2012; Gomez-Amo et al., 2011). The understanding of the relationship of pollutants concentration with, both synoptic and mesoscale circulation, is crucial for the air pollution monitoring. Weather and climate elements play a significant role in the emissions, the transport, the chemical transformations and the removal of pollutants. On a local scale, anthropogenic emissions may depend on meteorological variable (Nakamae and Shiotani, 2013; Kocak et al., 2012; Dall'Osto et al., 2010). A number of epidemiological studies have demonstrated that the atmospheric pollution has a correlation with the daily deaths and hospitalizations as a consequence of pulmonary and cardiac disease responses (Pederzoli et al., 2010). $\mathrm{O}_{3}$ is formed as a result of a cycle of photochemical reactions involving nitrogen Dioxide $\left(\mathrm{NO}_{2}\right)$ and Volatile Organic Compounds (VOC). The main reaction that forms $\mathrm{O}_{3}$ is the photolysis of $\mathrm{NO}_{2}$ to give $\mathrm{NO}$ and $\mathrm{O}$, with the $\mathrm{O}$ atom reacting with $\mathrm{O}_{2}$ to form $\mathrm{O}_{3}$, which can then react with $\mathrm{NO}$ to regenerate $\mathrm{NO}_{2}$. In the absence of other reactions, $\mathrm{NO}, \mathrm{NO}_{2}$ and $\mathrm{O}_{3}$ coexist in an equilibrium determined by the rate of $\mathrm{NO}_{2}$ photolysis in the presence of sunlight intensity. Photolysis of $\mathrm{O}_{3}$ by ultraviolet light yields a reactive $\mathrm{O}$ atom, which may lose energy by collision with $\mathrm{O}_{2}$ and $\mathrm{N}_{2}$ molecules in air and then react with $\mathrm{O}_{2}$ to re-form $\mathrm{O}_{3}$.

Corresponding Author: Karim Bouchlaghem, Université de Bretagne Occidentale, LBMS-EA 4325, Université Européenne de Bretagne, BP 93169, Rue de Kergoat, 29231, BREST Cedex 3, France Tel: +216- 97812449 
Increasing emissions of its precursors have caused surface ozone concentrations to increase (Carvalho et al., 2010). Ozone is considered to be a secondary pollutant with a short lifetime, due to its reactivity; however, under favorable conditions such as long range transport and sea-land breeze events it is possible to imply a spatial variability around urban and coastal areas which are the major sources of its precursors.

Dust continued to blow across northern Africa and the Mediterranean Sea. The persistent sources are located in the Northern Hemisphere, mainly in a broad "dust belt" that extends from the Meddle coast of North Africa over the Middle East (Rahoma, 2011).

The aim of the study of Lee et al. (2012) was to determine the monthly and seasonal variations of Air Pollution Index (API) at all monitoring stations in Johor. Time series models are discussed to analyze future air in Malaysia. The result indicates that the most polluted area in Johor located in Pasir Gudang with industrial activities. The review paper of Orji et al. (2012) came to conclusion that the Oil firms, remediation contractors and consultants using The Remediation by Enhanced Natural Attenuation (RENA) approach should employ strict monitoring during the process and also adhere strictly to standard practices and the mitigation measures for all the cases against RENA. The study of Lotfi et al. (2011) aims to analyze quality of life by concentrating on the socio-economic, physical-environmental and mental indexes. The research came to conclusion that the different neighborhoods of the town showed different level of quality of life which it leads to socio-economic disparities among the urban zones. So the priority of planning should concentrate on the areas where deprivation decreased the level of quality of life.

For this purpose, controlling air quality has turned out to be of primary importance as many sites surpass air quality standards, especially with respect to photo-oxidant (Cristofanelli and Bonasoni, 2009). The objective of this study is to investigate the origin of the polluted air masses in the Tunisian Mediterranean regions and to characterize the atmospheric conditions and the transport mechanisms that give rise to ozone events.

\section{MATERIALS AND METHODS}

The monitoring stations operated by the National Agency for Protection of Environment (NAPE) since 2002 until now are localized in the most Tunisian Mediterranean regions (35 fixed stations). A mobile laboratory is used to measure, in quarter hours average, pollutants levels in rural and urban sites. All instantaneous concentrations data can be controlled from the central station. The missing data in this study are due to the electricity cut-off. The monitoring stations used in this study (Bizerte ( $\left.37^{\circ} 27^{\prime} \mathrm{N}, 9^{\circ} 87^{\prime} \mathrm{E}\right)$; Kairouan ( $35^{\circ} 49^{\prime} \mathrm{N}$, $\left.10^{\circ} 38^{\prime}\right)$; Tunis $\left(36^{\circ} 49^{\prime} \mathrm{N}, 10^{\circ} 11^{\prime} \mathrm{E}\right)$ and Sfax town center $\left(34^{\circ} 74^{\prime} \mathrm{N}, 10^{\circ} 76^{\prime} \mathrm{E}\right)$ ) have been continuously operated since 2002 to measure pollutants concentrations (NO, $\mathrm{NO}_{2}, \mathrm{NO}_{\mathrm{x}}, \mathrm{SO}_{2}, \mathrm{O}_{3}$ and $\mathrm{PM}_{10}$ ). Each Pollutant's measurement instrument was based on standard methods (chemiluminescence, method, fluorescence method, photochemical method and the beta gauge principle, respectively) designed by the TAPI (2011). They have a detection limit inferior to $0.6 \mathrm{ppb}$ and a precision of $0.5 \%$. The detection of ozone molecules is based on absorption of $254 \mathrm{~nm} \mathrm{UV} \mathrm{light} \mathrm{thanks} \mathrm{to} \mathrm{an} \mathrm{internal} \mathrm{electronic}$ resonance of the $\mathrm{O}_{3}$ molecule. The Model 400A uses a mercury lamp constructed so that a large majority of the light emitted is at the $254 \mathrm{~nm}$ wavelength. Light from the lamp shines down a hollow quartz tube that is alternately filled with sample gas and then filled with gas scrubbed to remove ozone. The ratio of the intensity of light passing through the scrubbed gas to that of the sample forms a ratio I/Io. The Beer-Lambert equation calculates the concentration of ozone from the ratio of light intensities. The concentration of ozone does not only depend on the intensity ratio. Temperature and pressure influence the density of the sample. This effect is addressed by measuring temperature and pressure and including their values in the calculation. The intensity of light is converted into a voltage by the detector/preamp module. The voltage is converted into a number by a voltage-to-frequency converter. Moreover, the influence of atmospheric dynamics on the levels of air pollutants was investigated by means of back-trajectories analysis using the HYSPLIT (2011).

\section{RESULTS AND DISCUSSION}

The sites presented in this study are Mediterranean coastal cities with flat terrain. Here we are Analyzing samples of $\mathrm{O}_{3}$ surface concentrations during a summer period (2011) as a function of air mass back-trajectories reaching Tunisian regions.

\subsection{Wind Direction and its Impact on Ozone Concentration}

Differences of $\mathrm{O}_{3}$ concentration between locations seem to be associated with the proximity to the source emissions. For instance, episodes of long residence time of $\mathrm{O}_{3}$ were studied (from 01st June to 31 st July 2011) in Tunisian Mediterranean sites. Over this period, an increase of average daily $\mathrm{O}_{3}$ concentration 
was registered (up to $65 \mathrm{ppb} \mathrm{O}_{3}$ average hourly concentration in Sfax center. 2011 annual average $\mathrm{O}_{3}$ concentration is $25 \mathrm{ppb}$ ) compared to the average summer concentration (up to $30 \mathrm{ppb}$ ) (Fig. 1). First, a sample of back trajectory of European origin ending over the Mediterranean Tunisian regions on the studied period (July 2011) shows that the variability in $\mathrm{O}_{3}$ concentration is related to air masses coming from this continent (Fig. 2a). At a local scale, the NorthWest wind direction correlates well with $\mathrm{O}_{3}$ concentrations during the high episode (National meteorological data and NOAA ARL data).

\subsection{The Relation of Eastward Displacement of Dust with High $\mathrm{O}_{3}$ Levels}

A comparison with the back trajectories (www.arl.noaa.gov) and satellite images (www.nrlmry.navy.mil/aerosol) during the study period shows that the decrease in particulate levels and the increase of $\mathrm{O}_{3}$ concentration after the Saharan events were induced by the eastward displacement of the dust towards the eastern Mediterranean and owing to the influence of the arrival of the European air masse which is characterized by high $\mathrm{O}_{3}$ levels. During this period, the increase of surface $\mathrm{O}_{3}$ concentration may be due to the photochemical ozone production and the vertical extension of the mixed layer (up to $1500 \mathrm{~m}$ ) during hot summer, which promotes the fumigation of $\mathrm{O}_{3}$ and its precursors affecting the surface concentration. The Atlantic air masses related to cyclonic conditions during this period may be a traveling lane along which the ozone may be lifted above from the European emissions and transported to the Mediterranean regions. Gravity waves related with cold fronts and a high-pressure system favor the downward movement of air masses to the surface. The transportation of pollution from Europe resulted in surface $\mathrm{O}_{3}$ loading and high surface concentrations (up to $65 \mathrm{ppb}$ ) in the Mediterranean Tunisian sites causing the surpassing of the European standard limits $\left(120 \mu \mathrm{g} / \mathrm{m}^{3} / 8 \mathrm{~h}\right.$; the European Council Directive 2008/50/EC).

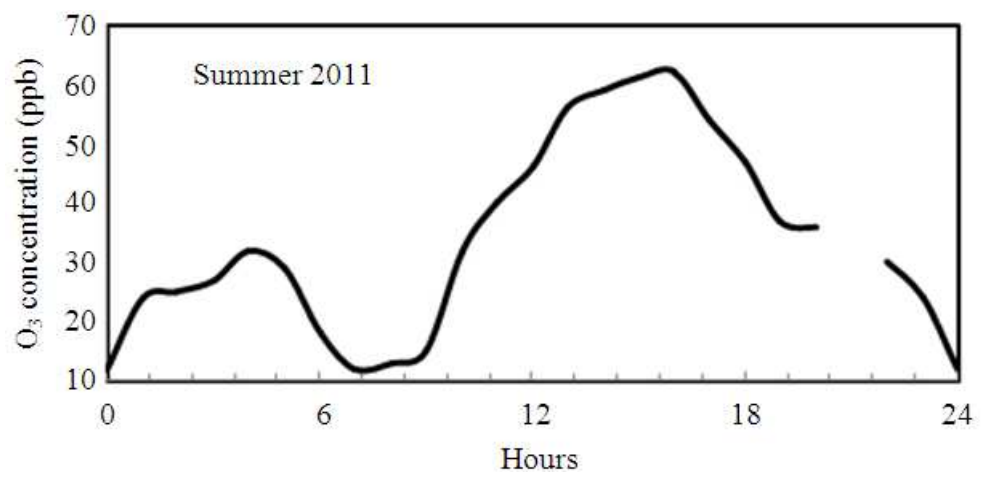

Fig. 1. Average daily ozone evolution in a Tunisian site (Sfax center) during 2011 summer period
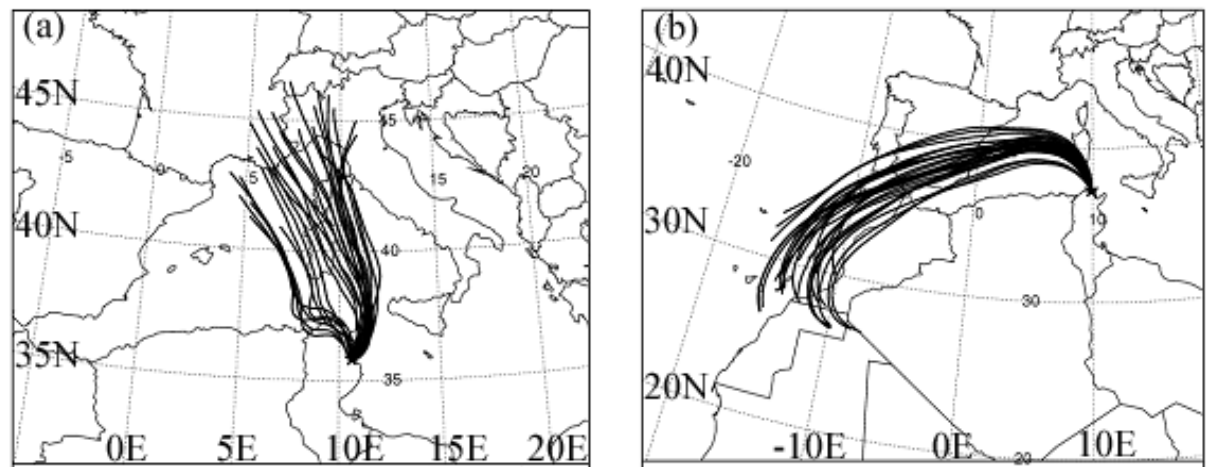

Fig. 2. Samples of back trajectory maps during (a) European event and (b) Saharan outbreak event of the studied period (July 2011) ending over the Mediterranean Tunisian regions (Bizerte and Kairouan) at $1500 \mathrm{~m}$ level and at $12 \mathrm{pm}$ (Local Time). ((NOAA)'s Air Resources Laboratory (ARL)) 


\subsection{The Saharan Dust Outbreak Influence on Surface Ozone Concentration}

High temperature characterizing the Mediterranean Tunisian sites improves photochemical events. Second, backward trajectories ending over the Tunisian sites at $1500 \mathrm{~m}$ altitude and at $12 \mathrm{pm}$ Local Time (LT) on the studied period (July 2011) show a samples of Saharan dust reaching Tunisian coasts during the same summer period when the synoptic condition switches to anticyclonic situation (Fig. 2b). At a local scale, the South-West wind direction correlates well with Saharan dust outbreak over the Mediterranean Tunisian coasts. This phenomenon results in a peak $\mathrm{PM}_{10}$ event reaching the highest daily values (by $160 \mu \mathrm{g} / \mathrm{m}^{3}$ ) and lower $\mathrm{O}_{3}$ concentration due to the influence of the relatively clean Saharan air. It is important to note that in this period the daily average $\mathrm{O}_{3}$ concentration recorded in Sfax city drops to about $20 \mathrm{ppb}$ (Fig. 3). As highlighted in Fig. 3, the Saharan dust outbreak may influence surface ozone concentration. In fact, the time evolution of ozone concentration shows that during the event of Saharan dust, daily $\mathrm{O}_{3}$ concentrations decreased $(20 \mathrm{ppb})$ in comparison with the average monthly concentration (up to $30 \mathrm{ppb}$ ). These provided the importance of chemical reactions and radiative impacts involving dust particles which may reduce the photochemical production of ozone. In fact, aerosol clouds reaching the Mediterranean regions can decrease the dispersion and absorption properties of the atmosphere to affect the changes of photochemical ozone production by absorbing and scattering solar radiation.

\subsection{Seasonal Variability of Ozone Concentration}

The depletion reaction of mineral dust reaching the surface level can reduce $\mathrm{O}_{3}$ precursors promoting the reduction of photochemical $\mathrm{O}_{3}$ concentration (Cristofanelli and Bonasoni, 2009). Figure 4 shows that hot season ozone concentrations (up to $45 \mathrm{ppb}$ ) were twice as greater than autumn and winter $\mathrm{O}_{3}$ concentrations (up to $22 \mathrm{ppb}$ ). There was a spring maximum followed by a second peak (up to $45 \mathrm{ppb}$ ) in summer period at the Tunisian monitoring stations. The continuity of the ozone maximum from spring to summer season shows that the photochemical production represents an important factor in the ozone concentration. The time series plot of ozone concentration (Fig. 5) shows a daily variation during winter and autumn seasons. The afternoon concentration (up to $38 \mathrm{ppb}$ ) was three times greater than those of the nocturnal (up to $12 \mathrm{ppb}$ ). Besides, nocturnal values do not change significantly during hot seasons.

\subsection{Daily and Nightly Ozone Values}

During the autumn and winter period, ozone minimum concentration (12 ppb) was registered during the nighttime. Figure 5 shows an ozone increase starting in the morning and a maximum in the afternoon followed by a drop until sunset. The morning rise could be attributed to the occurrence of mixing processes (mixing of cold and hot air masses leading to the increase of the boundary layer high). By this time, $\mathrm{O}_{3}$ is brought down from the reservoir layer as a result of vertical mixing due to the ground heating effect (Cristofanelli and Bonasoni, 2009). Simultaneously, fresh NO emissions (from Vehicular and industrial emissions as well as the influence of ships emissions characteristic of the Mediterranean area) and solar radiation promote photochemical ozone production. The period of powerful solar radiation (12-6 pm LT) coincides with the duration of ozone production and the concentration remains high. The ozone drop seen during the night was due to the solar radiation decrease and the diffusion of pollutants to the upper layers as a result of vertical mixing due to the ground heating effect.

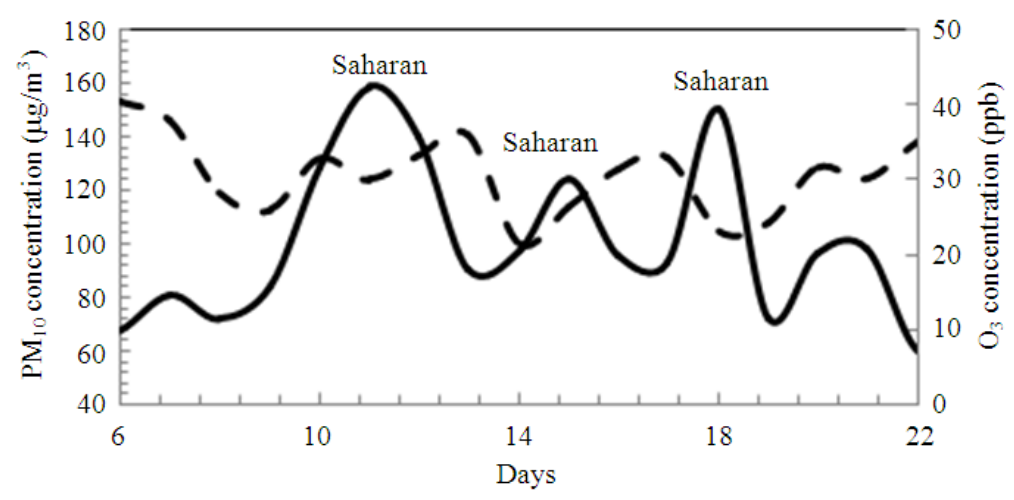

Fig. 3. Daily series plots of $\mathrm{PM}_{10}$ and $\mathrm{O}_{3}$ concentrations during Saharan events (from 6th to 22nd June 2011) at a coastal site (Sfax center). Time evolution of the Left y-axis is plotted with Solid line and the right one is plotted with a dashed line 
Karim Bouchlaghem et al. / American Journal of Environmental Science 9 (6): 537-543, 2013

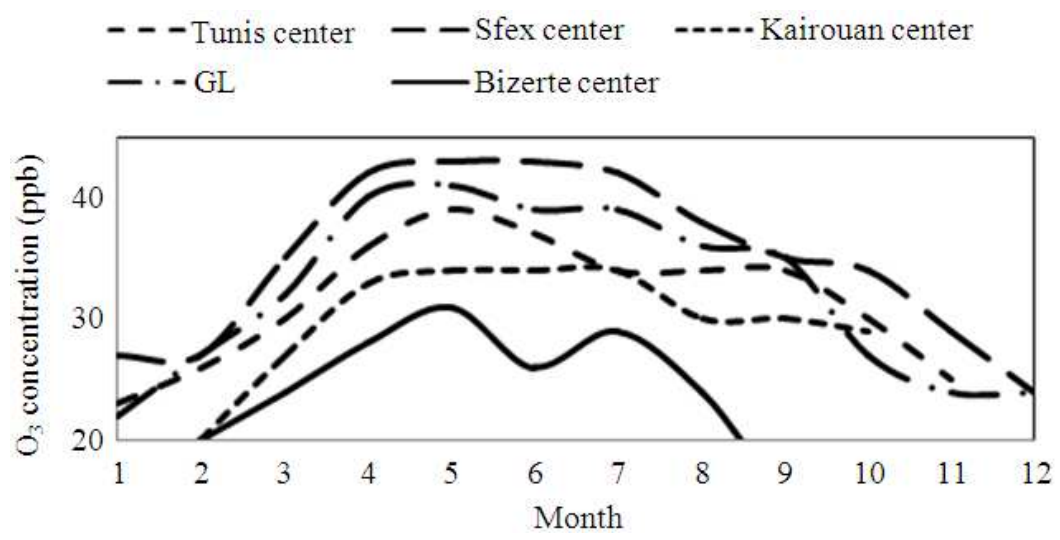

Fig. 4. Average seasonal variations of $\mathrm{O}_{3}$ concentration in Mediterranean Tunisian regions (2011 data)

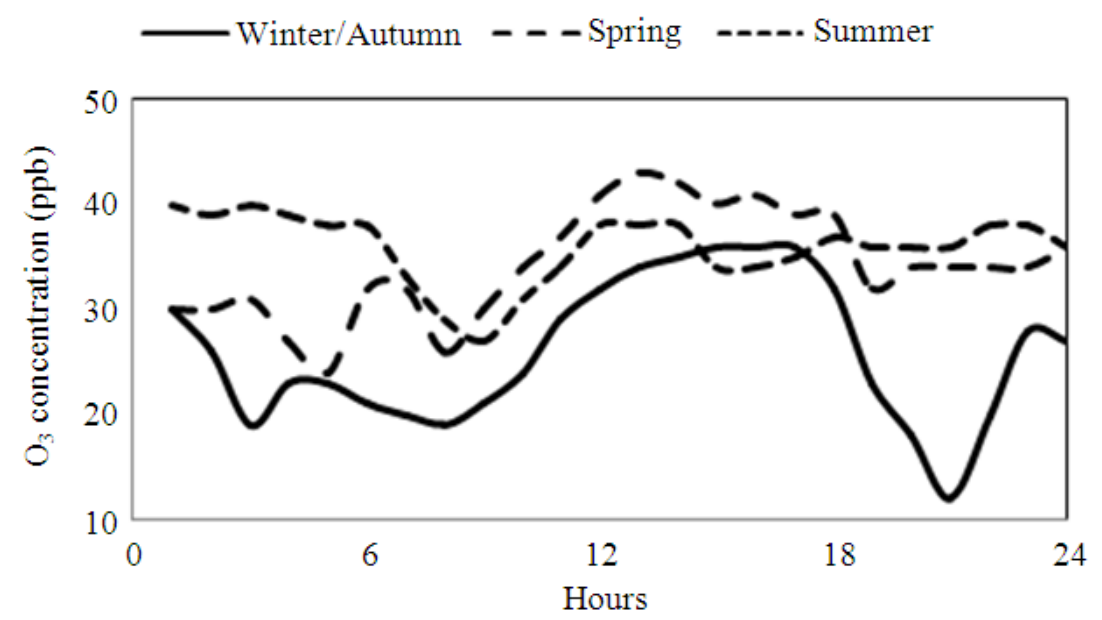

Fig. 5. Seasonal average daily variations of $\mathrm{O}_{3}$ concentration in Sfax center (2011 data)

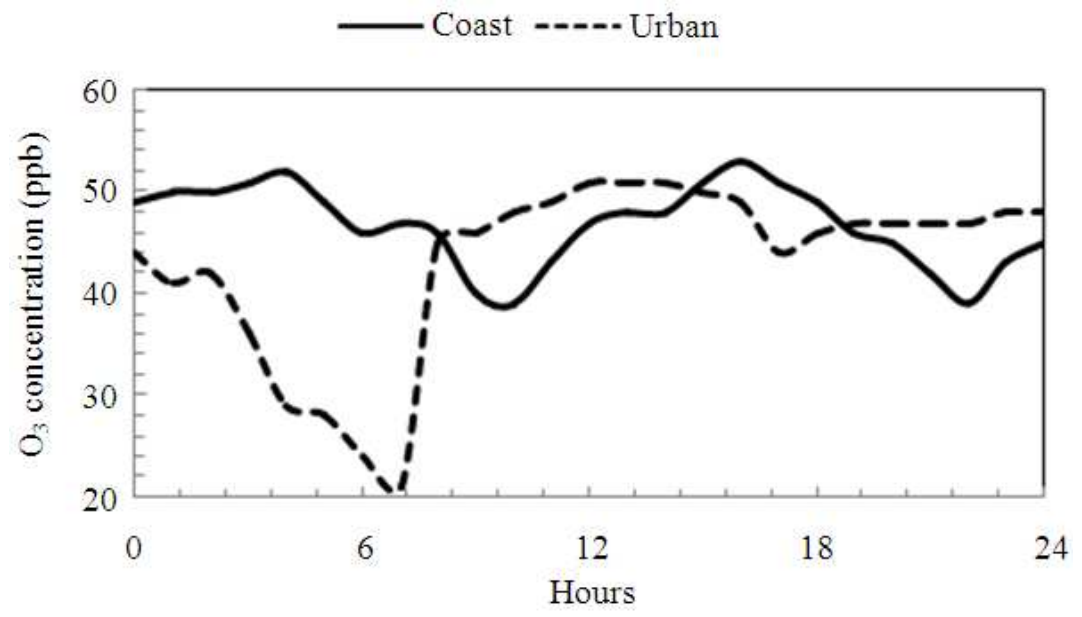

Fig. 6. Average daily ozone evolution at urban and coastal Tunisian sites 
By this period, NO emitted into the boundary layer, titrates ozone near the surface. The coastal sites showed small ozone concentration differences between day and night (Fig. 6). For the sake of brevity, we studied a coastal site with weak southeasterly wind providing the weather stability and accounting for the $\mathrm{O}_{3}$ uniform diurnal concentration. Besides, ozone precursor emission drops during the night. The combination of these factors result in the reduction of the destruction processes in night-time and the ozone concentration remained high (up to $40 \mathrm{ppb}$ ).

\subsection{Reasons for the Peaks and Drops of Daily Ozone Concentration}

In the urban site, the minimum $\mathrm{O}_{3}$ concentration (20 ppb) observed during the morning was caused by the destruction of ozone by its precursors (Fig. 6). In fact, the peaks of the ozone precursors were observed in the early morning corresponding to the rush hours enhanced by the lower height of the boundary layer at that time. During this period, the lowest ozone concentrations were observed in the urban site and could be proved by the highest traffic and the maximum ozone depletion (Cristofanelli and Bonasoni, 2009). Focusing on the afternoon hours (12-6 pm LT) of the day, the maximum height of the atmospheric boundary layer associated with the maximum solar radiation and vertical atmospheric mixing was observed and thus the measured values of atmospheric pollutants are represented with a homogenous distribution. The afternoon ozone precursor concentrations are lower than the rush hours levels while the maximum values (up to $55 \mathrm{ppb}$ ) of the secondary $\left(\mathrm{O}_{3}\right)$ pollutants are observed in the afternoon hours due to the intense photochemical activity.

\section{CONCLUSION}

In this study, we pointed out that the Saharan dust outbreaks and European events are expected to be an important natural event influencing the pollution in Tunisian regions. We have shown that pollutants concentration behaviour depet alends on the influence of a long range transport phenomenon. The transportation of pollution from Europe resulted in a surface $\mathrm{O}_{3}$ loading and a high surface concentration in the Mediterranean Tunisian sites causing the surpassing of the European standard limits. During summer, Ozone reaches its maximum concentration during the afternoon period under the influence of land-sea breeze recirculation and powerful photochemical activity. Saharan dust outbreaks promote $\mathrm{PM}_{10}$ events and reduce the ozone concentration over the Tunisian sites. This phenomenon was shown to be linked to lower $\mathrm{O}_{3}$ concentration due to the influence of the reactive and radiative impacts.

\section{REFERENCES}

Carnevale, C., G., Finzi, E., Pisoni, M., Volta and P. Kishcha et al., 2012. Integrating Saharan dust forecasts into a regional chemical transport model: A case study over Northern Italy. Sci. Total Environ., 417-418: 224-231. DOI: 10.1016/j.scitotenv.2011.12.031

Carvalho, A., A. Monteiro, I. Ribeiro, O. Tchepel and A.I. Miranda et al., 2010. High ozone levels in the northeast of Portugal: Analysis and characterization. Atmospheric Environ., 44: 1020-1031. DOI: 10.1016/j.atmosenv.2009.12.020

Cristofanelli, P. and P. Bonasoni, 2009. Background ozone in the southern Europe and Mediterranean area: Influence of the transport processes. Environ. Pollut., 157: 1399-1406. DOI: 10.1016/j.envpol.2008.09.017

Dall'Osto, M., R.M. Harrison, E.J. Highwood, C. O'Dowd and D. Ceburnis et al., 2010. Variation of the mixing state of Saharan dust particles with atmospheric transport. Atmospheric Environ., 44: 3135-3146. DOI: 10.1016/j.atmosenv.2010.05.030

Gomez-Amo, J.L., V. Pinti, T. Di Iorio, A. di Sarra and D. Meloni et al., 2011. The June 2007 Saharan dust event in the central Mediterranean: Observations and radiative effects in marine, urban and sub-urban environments. Atmospheric Environ., 45: 53855393. DOI: 10.1016/j.atmosenv.2011.06.045

HYSPLIT, 2011. Hybrid Single Particle Lagrangian Integrated Trajectory Model. Air Resources Laboratory.

Kocak, M., C. Theodosi, P. Zarmpas, M.J.M. Seguret and B. Herut et al., 2012. Influence of mineral dust transport on the chemical composition and physical properties of the Eastern Mediterranean aerosol. Atmospheric Environ., 57: 266-277. DOI: 10.1016/j.atmosenv.2012.04.006

Lee, M.H., N.H.A. Rahman, Suhartono, M.T. Latif and M.E. Nor et al., 2012. Seasonal ARIMA for forecasting air pollution index: A case study. Am. J. Applied Sci., 9: 570-578. DOI: 10.3844/ajassp.2012.570.578 
Lotfi, S., A. Faraji, H. Hataminejad and A. Pourahmad, 2011. A study of urban quality of life in a developing country. J. Soc. Sci., 7: 232-240. DOI: 10.3844/jssp.2011.232.240

Nakamae, K. and M. Shiotani, 2013. Interannual variability in Saharan dust over the North Atlantic Ocean and its relation to meteorological fields during northern winter. Atmospheric Res., 122: 336346. DOI: 10.1016/j.atmosres.2012.09.012

Orji, F.A., A.A. Ibiene and O.C. Ugbogu, 2012. Petroleum hydrocarbon pollution of mangrove swamps: The promises of remediation by enhanced natural attenuation. Am. J. Agric. Biol. Sci., 7: 207216. DOI: 10.3844 /ajabssp.2012.207.216
Pederzoli, A., M. Mircea, S. Finardi, A. di Sarra and G. Zanini, 2010. Quantification of Saharan dust contribution to PM10 concentrations over Italy during 2003-2005. Atmospheric Environ., 44: 41814190. DOI: $10.1016 /$ j.atmosenv.2010.07.031

Rahoma, U.A., 2011. Estimation of pathogenic microorganisms during atmospheric tempestat North Africa. Am. Med. J., 2: 1-6. DOI: 10.3844/amjsp.2011.1.6

TAPI, 2011. Teledyne Advanced Pollution Instrumentation Company. 